\title{
Use of the $\lambda$ Red-recombineering method for genetic engineering of Pantoea ananatis
}

\author{
Joanna I Katashkina1, Yoshihiko Hara², Lyubov I Golubeva*1, \\ Irina G Andreeva ${ }^{1}$, Tatiana M Kuvaeva ${ }^{1}$ and Sergey V Mashko ${ }^{1}$
}

\begin{abstract}
Address: ${ }^{1}$ Closed Joint-Stock Company "Ajinomoto-Genetika Research Institute", 1st Dorozhny Pr 1, Moscow 117545, Russia and ${ }^{2}$ Fermentation and Biotechnology Laboratories, Ajinomoto Co, Inc, 1-1 Suzuki-cho, Kawasaki-ku, Kawasaki 210-8681, Japan

Email: Joanna I Katashkina - joanna_katashkina@agri.ru; Yoshihiko Hara - yoshihiko_hara@ajinomoto.com; Lyubov I Golubeva* - luba_golubeva@agri.ru; Irina G Andreeva - irina_andreeva@agri.ru; Tatiana M Kuvaeva - Tatiana_Kuvaeva@agri.ru; Sergey V Mashko - sergey_mashko@agri.ru

* Corresponding author
\end{abstract}

Published: 23 April 2009

BMC Molecular Biology 2009, 10:34 doi:10.1186/147|-2199-10-34

This article is available from: http://www.biomedcentral.com//47I-2/99//0/34

(c) 2009 Katashkina et al; licensee BioMed Central Ltd.

This is an Open Access article distributed under the terms of the Creative Commons Attribution License (http://creativecommons.org/licenses/by/2.0), which permits unrestricted use, distribution, and reproduction in any medium, provided the original work is properly cited.
Received: 8 October 2008

Accepted: 23 April 2009

\begin{abstract}
Background: Pantoea ananatis, a member of the Enterobacteriacea family, is a new and promising subject for biotechnological research. Over recent years, impressive progress in its application to L-glutamate production has been achieved. Nevertheless, genetic and biotechnological studies of Pantoea ananatis have been impeded because of the absence of genetic tools for rapid construction of direct mutations in this bacterium. The $\lambda$ Red-recombineering technique previously developed in $E$. coli and used for gene inactivation in several other bacteria is a high-performance tool for rapid construction of precise genome modifications.

Results: In this study, the expression of $\lambda$ Red genes in $P$. ananatis was found to be highly toxic. A screening was performed to select mutants of $P$. ananatis that were resistant to the toxic affects of $\lambda$ Red. A mutant strain, $\mathrm{SCl7}(0)$ was identified that grew well under conditions of simultaneous expression of $\lambda \mathrm{gam}$, bet, and exo genes. Using this strain, procedures for fast introduction of multiple rearrangements to the Pantoea ananatis genome based on the $\lambda$ Red-dependent integration of the PCR-generated DNA fragments with as short as 40 bp flanking homologies have been demonstrated.

Conclusion: The $\lambda$ Red-recombineering technology was successfully used for rapid generation of chromosomal modifications in the specially selected $P$. ananatis recipient strain. The procedure of electro-transformation with chromosomal DNA has been developed for transfer of the marked mutation between different $P$. ananatis strains. Combination of these techniques with $\lambda \operatorname{lnt} / X$ isdependent excision of selective markers significantly accelerates basic research and construction of producing strains.
\end{abstract}

\section{Background}

Pantoea ananatis belongs to the Enterobacteriacea family. The P. ananatis strain AJ13355 (SC17) was isolated from soil in Iwata-shi (Shizuoka, Japan) as a bacterium able to grow at acidic $\mathrm{pH}$ and showing resistance to high concentrations of glutamic acid [1]. These physiological features made this organism an interesting object for biotechnological studies, and for this reason its genome has been 
sequenced by Ajinomoto Co. (unpublished results). Nevertheless, up to the recent past, the absence of efficient genetic tools has hampered manipulations of this bacterium and retarded both basic research and applied investigations.

Over the last decade [2-7], the most powerful method for generating a wide variety of DNA rearrangements in E. coli has been termed "recombineering" (recombinationmediated genetic engineering) [8]. The term generally refers to in vivo genetic engineering with DNA fragments carrying short homologies with a bacterial chromosome, using the proteins of a homologous recombination system of the bacteriophage $\lambda$ ( $\lambda$ Red system). Lambda red operon includes only three genes encoding Exo, Beta and Gam proteins. Gam inhibits the host nucleases, RecBCD and SbcCD, thereby protecting the dsDNA substrate for recombination $[9,10]$; Exo degrades linear dsDNA from each end in a $5^{\prime} \rightarrow 3^{\prime}$ direction, creating dsDNA with 3 ' single-stranded DNA tails [11-14]; and Beta stably binds a ssDNA greater than 35 nucleotides in length and mediates pairing the one with a complementary target [15-17].

The $\lambda$ Red-mediated recombineering technology developed initially for modification of the genome of Escherichia coli K12 [2,4-7], was later broadened to other E. coli strains including enteropathogenic ones [18], and to Salmonella $[19,20]$, Shigella $[21,22]$, Yersinia $[23,24]$, Pseudomonas [25], as well. Probably, one of the factors impeding application of this system in other hosts is the toxicity of expression of the $\lambda$ Red genes for the cells.

In the present study, to overcome this toxicity for Pantoea ananatis, the special strain resistant to simultaneous expression of the $\lambda$ Red genes was selected. Using this mutant, construction of all types of chromosomal rearrangements previously obtained in $E$. coli by recombineering was reproduced. The approach described may be used for adjusting the technology to other hosts.

\section{Results \\ Construction of the new broad-host-range $\lambda$ Red- expressing plasmid}

To provide regulated expression of the $\lambda$ Red genes in different bacteria, the plasmid pRSFRedTER [GenBank:F[347161] based on the broad-host-range replicon of RSF1010 [26] has been constructed (see Additional file $1)$. This plasmid is useful for $\lambda$ Red-mediated recombineering because: 1 ) the replicon is stably maintained in many Gram-negative [27] and some Gram-positive bacteria $[28] ; 2)$ the $\lambda$ Red genes are placed under the control of the $\mathrm{P}_{\text {lac } \mathrm{Uv} 5}$ promoter recognized by different bacterial RNA polymerases $[29,30] ; 3)$ the auto-regulated element $\mathrm{P}_{\text {lac UV5-lacI }}$ provides IPTG-inducible expression of the $\lambda$ Red genes with low basal level $[31]$; 4) the plasmid con- tains the levansucrase gene from B. subtilis allowing rapid and efficient recovery of this plasmid from the cells in a medium containing sucrose.

To test recombineering efficiency, pRSFRedTER mediated disruption of galK gene in E. coli MG1655 chromosome by integration of the PCR-generated DNA fragment carrying the $\mathrm{Km}^{\mathrm{R}}$ gene from pUC4K flanked by att $L_{\lambda}$ and $a t t R_{\lambda}$ sites $\left(a t t L_{\lambda}-\mathrm{Km}^{\mathrm{R}}-a t t R_{\lambda}\right)$ was performed. The constructed plasmid provided about 300 transformants per $10^{8}$ survivors following electroporation. A similar frequency was obtained when pKD46 plasmid [4] was used as $\lambda$ Redexpressing plasmid. In each case a chromosome structure of ten $\mathrm{Km}^{\mathrm{R}}$ colonies was confirmed with PCR analysis.

Another plasmid carrying $\lambda$ Red genes and named pRSFRedkan [GenBank:F]347162], has been constructed via substitution of $\mathrm{Cm}^{\mathrm{R}}$ and $B$. subtilis sacB genes by the $\mathrm{Km}^{\mathrm{R}}$ gene from pUC4K [32].

\section{Concerted expression of $\lambda$ Red genes is highly toxic for the P. ananatis wild-type cells}

Clones of $P$. ananatis SC17 strain [1] obtained after electroporation by pRSFRedTER and plated on a solid LBmedium supplemented with $\mathrm{Cm}(50 \mu \mathrm{g} / \mathrm{ml})$ were of very small size. Bacteria from these colonies grew very slowly in comparison with bacteria carrying pRSFsacB plasmid (see Additional file 1), which served as a vector for cloning of $\lambda$ Red genes. Addition of IPTG ( $1 \mathrm{mM}$ ) for induction of expression of $\lambda$ Red genes, led to complete cessation of the growth of pRSFRedTER containing cells. This effect was not detected for the cells carrying pRSFsacB and was based on the toxicity of the expression of $\lambda$ Red genes.

To establish which component of the $\lambda$ Red system caused the toxic effect, we constructed the pRSFGamBet [GenBank; $[\mathrm{F} 347163$ ] plasmid lacking the exo gene encoding 5' $\rightarrow$ 3' exonuclease.

It is well known that exonuclease activity is necessary for integration of dsDNAs only; integration of ssDNAs, such as chemically synthesized oligos, requires only recombinase (product of the bet gene, see [8]). To test the functional activity of the constructed pRSFGamBet, the plasmid was used to promote recombination between the artificial ss-oligos comprising two 36-nt homologies to the galK sequences and chromosome of the E. coli MG1655galK:: $\left(a t t L_{\lambda}-\mathrm{Km}^{\mathrm{R}}-a t t R_{\lambda}\right)$ strain. As a result of recombination a native structure of galK gene was restored. Between (1.5-2.5) $\times 10^{4} \mathrm{Gal}^{+}$integrants per $10^{8}$ survivors following electroporation were obtained in three independent experiments.

When introduced into $P$. ananatis SC17 strain, the pRSFGamBet plasmid did not inhibit cell growth even under 
the induced conditions (in the presence of $1 \mathrm{mM}$ IPTG). Hence, the detected toxicity of pRSFRedTER was apparently caused by exo expression, or by simultaneous expression of all $\lambda$ Red genes in $P$. ananatis cells.

\section{Selection of the recipient strain for $\lambda$ Red-mediated recombineering in $\mathrm{P}$. ananatis}

A mutant $P$. ananatis strain, SC17(0), resistant to concerted expression of all $\lambda$ Red genes, and thus manifesting the properties of a suitable recipient strain for $\lambda$ Red-mediated integration of the linear DNAs into the chromosome, was obtained as follows. About 10 clones from $10^{6}$ transformants obtained after electroporation of $P$. ananatis SC17 strain by pRSFRedTER, were of larger size after being plated on LB-agar with Cm. In LB-broth, bacteria from the "large" clones had a growth rate similar to the control strain with the pRSFsacB plasmid, and induction of the $\lambda$ Red genes by IPTG caused only slight retardation in the growth of these cells.

Several of the selected "large" clones were cured from the plasmid on LB-agar containing sucrose, and re-transformed with pRSFRedTER. All clones grown after this retransformation were of large size, similar to the parental clones. Three of the pRSFRedTER transformants that grew well were used as recipient strains for $\lambda$ Red-mediated disruption of hisD gene. A PCR substrate, containing (att $L_{\lambda^{-}}$ $\mathrm{Km}^{\mathrm{R}}$-attR $\mathrm{R}_{\lambda}$ )-marker flanked by 40 -bp homologous to the his $D$ gene, was electroporated into these strains. From 100 to $150 \mathrm{Km}^{\mathrm{R}} \mathrm{His}^{-}$clones per $10^{8}$ survivors following electroporation were obtained for each tested recipient strain. The insertion of the marker in the desired point of hisD gene was confirmed by PCR-analysis of 10 independent $\mathrm{Km}^{\mathrm{R}} \mathrm{His}^{-}$clones in each case. The observed integration frequency was similar to that obtained in the corresponding experiments with E. coli [4-6]. One of the plasmid-less strain used as a recipient in this experiment was named as SC17(0), and the obtained hisD strain constructed on its basis - as SC17(0)hisD::(attL $\left.{ }_{\lambda}-\mathrm{Km}^{\mathrm{R}}-a t t R_{\lambda}\right)$.

We tried to determine the nature of the mutation/mutations that provide resistance to concerted expression of $\lambda$ Red genes to $P$. ananatis. There were no auxotrophic properties for SC17(0) strain growing on the M9 minimal media, supplemented with different carbon sources, in comparison with initial SC17 strain [1]. One of the possible explanations for the SC17(0) resistance is the reduced level of accumulation of $\lambda$ Red proteins in this strain. To test the level of accumulation of $\lambda$ Red proteins in SC17 and SC17(0), we performed SDS-PAGE of extracts of both strains carrying pRSFRedTER plasmid. Unfortunately, bands of $\lambda$ Red proteins were not detected among the total cellular proteins even in conditions of IPTG induction for the both plasmid-carrier strains. The reduction in level of accumulation of $\lambda$ Red proteins in SC17(0) strain, also, can be caused by decreased copy-number of RSF1010-replicon carrying plasmids in this strain. However, no reliable change in copy-number of pRSFsacB plasmid extracted from the cells of $P$. ananatis SC17 or SC17(0) strains could be experimentally found. On the other hand, the toxicity of the expression of $\lambda$ Red genes has been detected for the plasmid-carrier cells of SC17 strain grown even without IPTG addition to the medium. In this case the transcription of the operon mediated by auto-regulated $\mathrm{P}_{\text {lacuv5-lacI }}$ genetic element has to be tightly repressed. According to Skorokhodova et al. addition of $1 \mathrm{mM}$ IPTG to the culture medium provides an increase of transcriptional level up to 10-20 fold [31]. But, the transcription level of $\lambda$ Red genes under such conditions is not toxic for SC17(0). Hence, it is unlikely, that the synthesis of $\lambda$ Red proteins in SC17 under the repressed conditions could be significantly higher than in SC17(0) after induction.

Perhaps, mutation/mutations that are present in the genome of the SC17(0) strain does not affect most of the genes encoding factors of global cellular regulation. At least, the patterns of total cellular proteins separated by 2D-PAGE in such a fashion that about 350 of individual polypeptides could be quantitatively analyzed [33], were not different for the SC17 and SC17(0) strains (data not shown).

Thus, the molecular mechanism of the resistance of the mutant SC17(0) strain to concerted expression of all $\lambda$ Red genes is unknown as yet. Nevertheless, as will be shown below, various $\lambda$ Red-driven modifications of bacterial chromosome could be provided on the basis of this selected strain.

\section{Use of the combined $\lambda$ Red-Int/Xis system for introduction of multiple modifications}

Earlier, a $\lambda$ Int/Xis-driven system for removing the markers from $E$. coli chromosome was constructed, similar to one developed by Peredelchuk \& Bennet $[34,35]$. It comprised of the plasmids carrying removable markers of $\mathrm{Km}^{\mathrm{R}}$ or $\mathrm{Cm}^{\mathrm{R}}$ flanked by $a t t L_{\lambda}$ and $a t t R_{\lambda}$ sites and the plasmid pMW-intxis-ts with thermo-sensitive pSC101-like replicon. This plasmid provided thermo-inducible expression of the xis-int genes under the control of $\lambda \mathrm{P}_{\mathrm{R}}$ promoter regulated by the temperature sensitive $\lambda$ CIts857 repressor. Even being partially induced at $37^{\circ} \mathrm{C}$, this system provided a high frequency (about $30 \%$ ) of marker excision in E. coli. The high frequency of marker eviction at $+37^{\circ} \mathrm{C}$ was very important for use of the system in $P$. ananatis because this bacterium has a lower temperature optimum than E. coli and cannot grow at $42^{\circ} \mathrm{C}$ (the standard temperature for temperature sensitive $\lambda$ CIts 857 repressor inactivation). 
The pMW-intxis-ts plasmid contains $\mathrm{Ap}^{\mathrm{R}}$ gene as a selective marker that was not practicable for $P$. ananatis because of its high natural resistance to Ap. For this reason, we have substituted this marker with the $\mathrm{Cm}^{\mathrm{R}}$ gene. The resulting plasmid (pMW-intxis-cat) was introduced to the SC17(0)hisD:: $\left(a t t L_{\lambda}-\mathrm{Km}^{\mathrm{R}}-a t t R_{\lambda}\right)$ strain described above by electroporation. More than $30 \%$ of the transformants grown at $37^{\circ} \mathrm{C}$ on the plates containing LB-agar with $\mathrm{Cm}$ had lost the $\mathrm{Km}$ resistance. Loss of the $\mathrm{Km}^{\mathrm{R}}$ cassette in the kanamycin-sensitive colonies was verified by PCR. Thus, the $\mathrm{Km}^{\mathrm{R}}$ cassette can be used in the next step of the chromosomal modifications of this strain (Fig. 1A). Curing of the $\mathrm{Km}^{\mathrm{S}}$ clones from the pMW-intxis-cat plasmid (with a frequency of $10 \%$ ) was performed by re-streaking bacteria

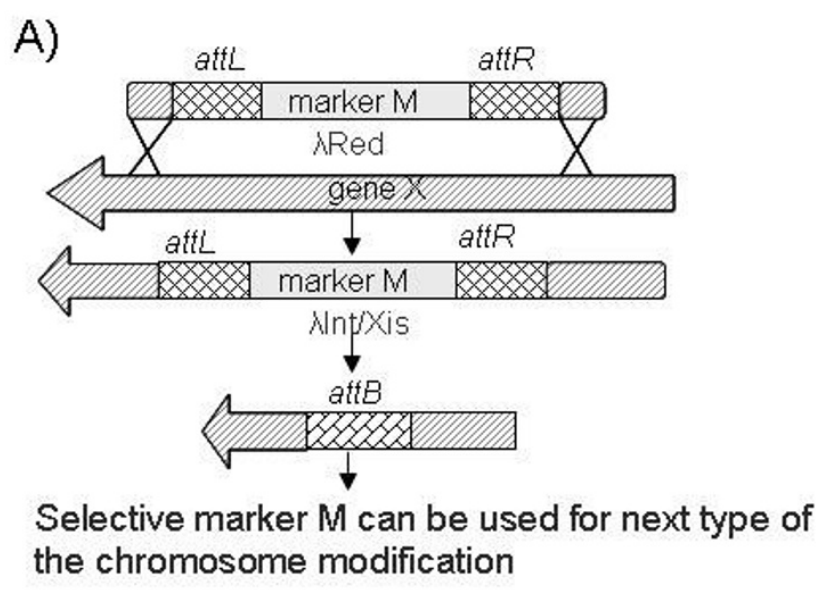

B)

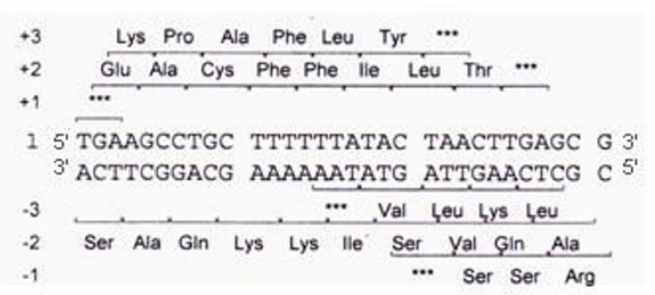

Figure I

Scheme of a construction of multiple chromosomal modifications, using the combined $\lambda$ Red-Int/Xis system. A) Selective marker $M$ flanked by $a t t L_{\lambda} / a t t R_{\lambda}$ is used for introduction of an appropriate mutation into the chromosome by $\lambda$ Red-dependent recombination. Then the marker is eliminated from the chromosome by $\lambda \operatorname{lnt} / \mathrm{X}$ is site-specific recombination. As a result, only the $3 \mathrm{I}$ bp long attB sequence linked to the mutation remains in the chromosome. Selective marker $M$ can then be used in the next step of the introduction of multiple chromosomal modifications. B) The sequence of the $a t t B_{\lambda}$ site. One of the six ORFs provided by this sequence does not contain stop codons. Hence, it is possible to design an "in-frame" deletion of a gene.

Asterisks mark stop codons. on LB-agar without antibiotic followed by cultivation at $37^{\circ} \mathrm{C}$.

The $a t t B_{\lambda}$ site ( 31 bp in length), remaining in the chromosome after marker excision, contains six possible reading frames. One of these reading frames does not contain stop codons (Fig. 1B). Therefore, usage of the removable markers flanked with $a t t L_{\lambda}$ and $a t t R_{\lambda}$ sites allows design and construction of "in frame" deletions.

Using the $\lambda$ Red-driven chromosomal modification followed by $\lambda$ Int/Xis-mediated excision of the selective marker, it was possible to provide, step-by-step, the multiple chromosomal modifications in P. ananatis SC17(0) strain. This approach was repeatedly used for different modifications. Among them were 1) combinations of the simple or "in frame" deletions of several genes/operons; 2 ) integration of the marked heterologous genes into the chromosome of $P$. ananatis and 3) modification of the regulatory regions of the genes of interest [36]. Up to the present, several $P$. ananatis strains carrying more than 10 different modifications have been constructed using this strategy; the presence of multiple $a t t B_{\lambda}$ sites in their chromosomes did not hamper the repeated exploitation of this system.

\section{Transfer of marked mutations by electroporation of chromosomal DNA}

General transduction is the most efficient and popular method for transfer of mutations between different $E$. coli strains. Although $P$. ananatis and E. coli are close relatives, the known E. coli transducing phages cannot infect $P$. ananatis cells. Therefore, development of another method for transfer of mutations between $P$. ananatis strains was necessary.

The electroporation of genomic DNA has been described for the transfer of genetic markers between different backgrounds of E. coli and Pseudomonas [37,38]. We tried to apply this technique to $P$. ananatis. The SC17(0)hisD:: $\left(a t t L_{\lambda}-\mathrm{Km}^{\mathrm{R}}-a t t R_{\lambda}\right)$ strain was used as a donor of $\mathrm{Km}^{\mathrm{R}}$ marker. Wild type strain SC17 was used as a recipient for electro-transformation of chromosomal DNA.

Previously, it was shown that special electroporation conditions are needed for the transformation of E. coli cells with large DNA molecules (see [39] for details). Different cultivation conditions of recipient strain and parameters of electroporation (electric field strength - E, time constant $-\tau$ ) were tested. For $P$. ananatis, the highest yield of integrants (about $100 \mathrm{Km}^{\mathrm{R}} \mathrm{His}^{-}$integrants per $10^{8}$ survivors following electroporation) was obtained under the following conditions. Recipient strain was grown up to absorbance of $0.8-1.0$. Then electro-competent cells 
were prepared using $10 \mathrm{ml}$ of culture as described in the "Plasmid electro-transformation" section (see "Methods"). Electroporation was performed at $\mathrm{E}=12.5 \mathrm{kV} / \mathrm{cm}$ and $\tau=10 \mathrm{msec}$ (resistance of $400 \Omega$ and capacity of 25 $\mu \mathrm{F})$. Electro-transformation with chromosomal DNA is very fast method: all procedures, including DNA isolation and electroporation, can be performed in one day.

We found that marked chromosomal modification, obtained in $P$. ananatis SC17(0) strain via $\lambda$ Red-recombineering method, could be easily transferred into the wild type SC17 strain by electroporation of chromosomal DNA. At the time of writing up to ten different mutations had been combined in the chromosome of the SC17 strain by repeated electro-transformation with chromosomal DNA followed by $\lambda$ Int/Xis-driven excision of selective marker. The frequency of marked mutation transfer varied from several up to several hundreds of integrants per trial.

\section{Two-step $\lambda$ Red-mediated introduction of unmarked mutations into $P$. ananatis chromosome}

A two-step $\lambda$ Red-mediated procedure for the introduction of unmarked mutations was elaborated for $P$. ananatis SC17(0). It comprises: 1) $\lambda$ Red-driven insertion of dual selective/counter-selective marker into the desired point;
2) elimination of the marker via $\lambda$ Red-mediated integration of the short dsDNA fragment containing the mutation of interest flanked with sites homologous to the appropriate target. Such an approach based on ET-recombination or $\lambda$ Red-recombination was previously exploited for introduction of the unmarked mutations in E. coli $[40,41]$. One of the most popular counter-selective markers used for this purpose is the $s a c B$ gene from $B$. subtilis, whose introduction imparts sucrose sensitivity to the bacterium.

To create a template for the PCR amplification of the dual selective/counter-selective marker, $c a t / s a c B$, the pRSFPlacsacB plasmid was constructed. The cassette $\mathrm{P}_{\text {lacuv5 }}$-sacB-cat was amplified with primers containing 36-nt homologies to the target on their 5'-ends, and integrated into SmaI recognition site located in hisD gene using SC17(0) harboring pRSFRedkan as a recipient and the cat gene in the cassette, as the selective marker. A short 170-bp long dsDNA fragment harboring an appropriate mutation and 82-bp long flanks homologous to the target region has been constructed (Fig. 2A). The desired modification of bacterial chromosome (substitution of the artificial XhoI for the native SmaI site) was finally achieved via the $\lambda$ Redmediated integration of the obtained DNA fragment accompanied by elimination of $\mathrm{P}_{\text {lac } \mathrm{UV} 5}-\mathrm{sacB}$-cat, using $s a c B$
A)

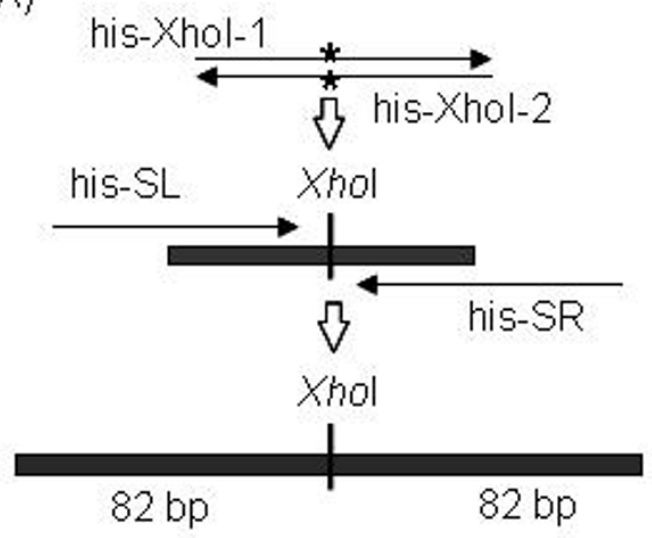

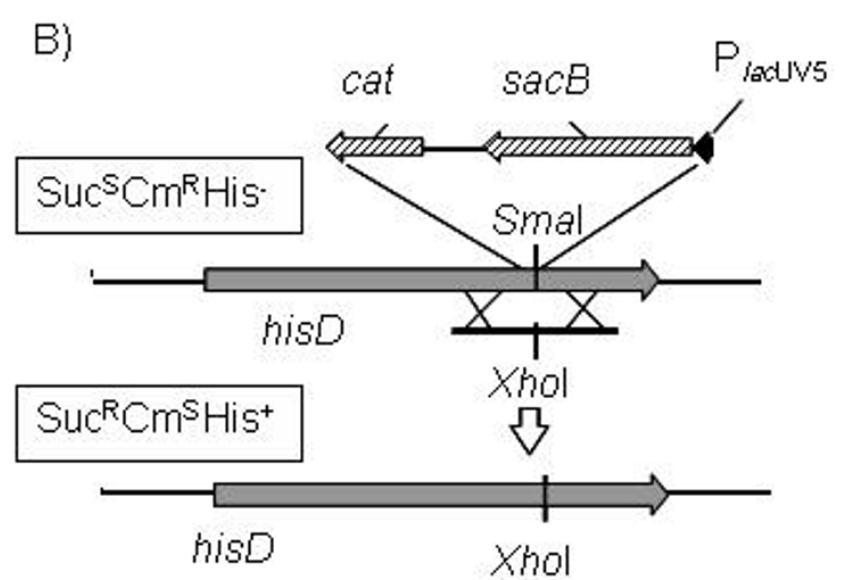

Figure 2

Construction of the unmarked nucleotide exchange in the $\boldsymbol{P}$. ananatis his $D$ gene. A) Construction of a dsDNA fragment with appropriate mutation in the center. First, his-Xhol-I and his-Xhol-2 oligos are annealed to each other. The nucleotide exchange of interest included in the sequence of his-Xhol-I/his-Xho2 olig is indicated by asterisks. The resulting dsDNA fragment is then used as DNA-template for PCR-amplification with his-SL and his-SR oligos. As a result a linear dsDNA fragment, harboring a Xhol restriction site and 82 bp long arms homologous to the target region of his $D$ gene, was obtained. B) The cassette containing dual selective/contra-selective marker is integrated into the target point of his $D$ gene. The constructed in vitro linear dsDNA fragment or ssDNA harboring appropriate mutation in the center is then integrated into the chromosome of this strain by the $\lambda$ Red recombination system. As a result, the dual selective/contra-selective marker is eliminated from the chromosome with simultaneous introduction of the desired mutation into the hisD gene. This mutation leads to substitution of the native Smal restriction site by the Xhol restriction site and restoration of the amino-acid sequence of HisD protein. Integrants are selected as colonies resistant to sucrose. Such colonies are subsequently tested for $\mathrm{Cm}$ sensitivity, ability for growth without histidine and presence of Xhol restriction site in the target chromosome point. 
gene for counter-selection (Fig. 2B). The integrants of interest were found with a rather high frequency $(25 \%)$ among the clones grown on LB-agar containing 30\% sucrose.

This procedure could be applied for introduction of unmarked mutations to the genome of SC17(0) strain. Transfer of the obtained unmarked mutations to other strains by electro-transformation with chromosomal DNA is difficult because of impossibility of direct selection of integrants. Hence, to provide construction of unmarked mutations in the genome of the P. ananatis strains, sensitive to expression of all $\lambda$ Red genes, we performed the method of $\lambda$ Beta-driven integration of single-stranded oligos into the chromosome of SC17 strain.

\section{$\lambda$ Beta-driven integration of single-stranded oligos}

As mentioned above, ssDNAs, e.g. oligos containing short flanks homologous to the target site, can be integrated into the E. coli chromosome using only the product of the $\lambda$ bet gene [8]. As the expression of gam and bet genes from pRSFGamBet plasmid was not toxic towards $P$. ananatis SC17 even under induced conditions, we tried to perform $\lambda$ Beta-driven integration of oligos into the chromosome of this strain.

The hisD:: $\mathrm{P}_{\text {lac Uv5 }}$-sacB-cat chromosomal modification was transferred into the SC17 strain by electro-transformation with genomic DNA isolated from SC17(0)hisD::: $\mathrm{P}_{\text {lacuv5 }}{ }^{-}$ sacB-cat strain. The resulting strain, selected on LB medium supplemented with $\mathrm{Cm}$, was named SC17hisD::P lacuv5-sacB-cat. The pRSFGamBet-kan [GenBank:Fl347164] plasmid was constructed by substitution of $s a c B$ and cat genes of pRSFGamBet for the $\mathrm{Km}^{\mathrm{R}}$ gene from pUC4K. This plasmid was introduced to the obtained SC17hisD:: $\mathrm{P}_{\text {lac UV5 }}$-sacB-cat strain. It is known from the literature $[8,42]$ that the efficiency of $\lambda$ Reddependent integration of the oligos depends on a direction of replication through the recombination site. The direction of replication at the hisD locus in the P. ananatis chromosome is not known. Hence, the plasmid-carrier cells were independently electroporated with hisD-XhoI-1 and hisD-XhoI-2 ss-oligos complementary to each other. Cells were plated on LB medium containing 30\% sucrose. No colonies were observed after 24-hour cultivation when hisD-Xhol-2 olig was used for electroporation. About 200 clones were obtained after electro-transformation with hisD-Xhol-1 olig. To test the phenotype of the obtained transformants, 100 clones were replicated on the following solid mediums: LB medium supplemented with 30\% sucrose, LB medium supplemented with $\mathrm{Cm}$ and $\mathrm{M} 9 \mathrm{~min}-$ imal medium. Seven of the tested clones had Suc ${ }^{\mathrm{R}} \mathrm{Cm}-$ ${ }^{\mathrm{s}} \mathrm{His}^{+}$phenotype. These colonies were further verified by PCR and restriction of the amplified product. The presence of the expected mutation (substitution of the SmaI by XhoI recognition site) was confirmed in all of the seven Suc $^{\mathrm{R}} \mathrm{Cm}^{\mathrm{S}} \mathrm{His}^{+}$clones.

Although the frequency of selection of the desired mutation was not high, in principle, $\lambda$ Beta-dependent integration of ssDNAs allowed the construction of the unmarked mutations in the $P$. ananatis.

\section{Discussion}

It is currently well established that high-frequency recombination between short homologies can be catalyzed in $E$. coli cells by the $\lambda$ Red functions [4-7,43-45]. Unfortunately, up to the present, the range of bacteria for which this system has been utilized is limited. The main goal of the present study was to widen use of the $\lambda$ Red-recombineering technology to $P$. ananatis, a bacterium of interest in the field of metabolic engineering. A broad-hostrange $\lambda$ Red-expressing plasmid useful for $P$. ananatis was constructed. The observed general toxicity of simultaneous expression of the $\lambda$ gam, bet, and exo genes for $P$. ananatis SC17 cells was overcome by selection of the special recipient, $\mathrm{SC} 17(0)$.

It is known that expression of $\lambda$ Red functions in $E$. coli cells can lead to toxic effects $[46,47]$. Certainly, expression of $\lambda$ Red genes has been investigated for $E$. coli in detail. In addition to its direct influence on traditional recombination pathways due to inhibition of RecBCD and SbcCD nucleases by $\lambda$ Gam, the activity of $\lambda$ Red proteins can interfere with the processes of replication and repair (see, $[48,49]$ for reviews). For example, prolonged expression of gam gene could lead to formation of linear multimers of high, medium and low copy-number plasmids, and, even, of minichromosomes [50-53]. Expression of exo gene in addition to gam enhances this effect $[50,52]$. The plasmid linear multimers, also, may interfere with $\lambda$ Redrecombination [18]. Murphy and co-workers showed that extended expression of $\lambda$ Red-recombination functions could significantly induce a spontaneous mutagenesis, probably caused by interfering with mismatch repair UvrD-dependent pathway of E. coli [18].

Toxicity of expression of $\lambda$ Red genes for the bacteria closely related to $E$. coli, but differing in the enzymes of replication, recombination and reparation, could not be predicted in advanced, as in the case of $P$. ananatis SC17. It is difficult, as well, to give an univocal explanation of how $\lambda$ Red-mediated toxicity could be overcome. It seems that the decrease of this toxicity could be based on (i) lower intracellular level of $\lambda$ Red proteins in the mutant cell, caused by reduced level in the synthesis of $\lambda$ Red proteins or by increased efficiency of the specific proteolysis of $\lambda$ Red proteins, (ii) decreased affinity of specific targets for interaction with $\lambda$ Red proteins or increased level of biosynthesis of these targets. As for the P. ananatis mutant 
strain obtained, both variants of the explanation may be possible. As mentioned in the Results section, it is not very probable that SC17(0) strain possesses reduced level of the synthesis of $\lambda$ Red proteins. But this possibility can not be completely rejected.

Nevertheless, even without information concerning the nature of the SC17(0) mutation, it is possible to use the corresponding strain for the desired $\lambda$ Red-mediated rearrangements of $P$. ananatis chtomosome. All types of chromosome modifications constructed in $E$. coli by the $\lambda$ Redmediated recombineering, have been successfully reproduced in SC17(0) with pRSFRedTER as $\lambda$ Red-expressing plasmid. Typically, the yield of recombinants varied from several tens to several hundreds per trial.

Using SC17(0) as the initial recipient for $\lambda$ Red-promoting modifications it is subsequently possible to transfer the marked mutation to other $P$. ananatis strains of interest using the method of electro-transformation with chromosomal DNA. This method is a unique way to combine the set of marked mutations constructed in different $P$. ananatis strains into a single strain. In addition, potentially, cotransfer of rather closed mutations could be prevented by digestion of the chromosomal DNA by the appropriate restriction endonucleases, whose recognition sites are located between the mutations.

As the number of combined mutations of interest exceeds the number of available antibiotic resistance markers, curing of the intermediate strains from the used selective markers is necessary. Moreover, the presence of antibiotic resistance genes in the genomes of the industrial strains is rigorously restricted by the legislations of different countries. A wide variety of systems for marker curing based on the site-specific recombination systems (Cre/lox, Flp/FRT) are well-known [54-57]. These systems provide "symmetrical" recombination reaction between two identical sites flanking the removing marker, e.g. FRTxFRT = 2FRT. In this case, after removing the marker, the active site remains in the chromosome. Repeated action of such systems can lead to inversion or deletion of extended chromosomal fragments caused by site-specific recombination between the sites remaining at different points in the chromosome. Therefore, use of systems providing "asymmetrical" recombination reaction would be preferable. One such system is the site-specific recombination system of $\lambda$ phage. It includes the Int and Xis proteins encoded by int and $x$ is genes that, together with the host factors (IHF, RecA and Fis), provide the following reaction: $a t t L_{\lambda} \mathrm{x} a t t R_{\lambda}$ $=a t t P_{\lambda}+\mathrm{attB}_{\lambda}$. Peredelchuk \& Bennet [34] were the first who used this system for removal of the selective markers flanked by $a t t L_{\lambda}$ and $a t t R_{\lambda}$ sites. The $a t t B_{\lambda}$ site remaining in the chromosome after marker excision cannot recombine with $a t t L_{\lambda}$ or $a t t R_{\lambda}$ site in the next steps of strain construc- tion. Thus, repeated action of the system would not influence the strain stability. Certainly, residual $a t t B_{\lambda}$ sites could recombine with each other via host general recombination system or provoke replication errors, especially if many left over scars $\left(a t t B_{\lambda}\right)$ are presented in chromosome and their positions were rather close to each other. Such events would lead to deletions of chromosomal fragments.

We adjusted the $\lambda$ Int/Xis-dependent system for use in high-efficient marker excision in $P$. ananatis. Note that it is also possible, in particular, to design marker-less strains, carrying "in-frame" deletions.

Finally, the two-step procedure for introducing the unmarked mutations into the $P$. ananatis genome was demonstrated using $B$. subtilis sacB gene as a counter-selective marker. Desirable mutants were achieved at the second stage via $\lambda$ Red-mediated integration of the short dsDNA in SC17(0) or ssDNA in any other $P$. ananatis strain carrying the dual selective/counter-selective marker in the target point of the genome.

Up to the present, the developed $\lambda$ Red-mediated method has been used for deletion of more than $50 \mathrm{P}$. ananatis genes whose products were involved in central metabolism, respiration, transcription regulation, etc. Several marker-less $P$. ananatis strains carrying multiple $(>10)$ different chromosomal modifications including "in-frame" deletions, point mutations, rearrangements of regulatory regions, in particular, were constructed for basic research and applied purposes using combined application of the $\lambda$ Red-Int/Xis systems and electro-transformation with chromosomal DNA.

\section{Conclusion}

The $\lambda$ Red-mediated recombineering has been adjusted for rapid and efficient construction of genome rearrangements in $P$. ananatis. In combination with the established procedures of $\lambda$ Int/Xis-dependent marker elimination and electro-transformation with chromosomal DNA, this method provides a simple route to obtaining marker-less strains carrying multiple mutations of different types (deletions, substitutions of regulatory regions, integration of heterologous genes, and point mutations). The described approach of selection of the recipient strain resistant to expression of $\lambda$ Red genes could be useful in exploiting $\lambda$ Red-recombineering in other bacteria.

\section{Methods \\ Strains and plasmids}

Strains and plasmids used or generated in this study are listed in Table 1. A detailed description of plasmids obtained in this work is in Additional file 1. 
Table I: Strains and plasmids used or generated in this study.

\begin{tabular}{|c|c|c|}
\hline Name & Main characteristics/accession number & Source or reference \\
\hline \multicolumn{3}{|l|}{ Strains } \\
\hline Pantoea ananatis SCI7 (AJI3355) & mutant with decreased secretion of mucus & {$[1]$} \\
\hline Pantoea ananatis $\mathrm{SCI}(0)$ & Derivative of $\mathrm{SCI} 7$ resistant to expression of $\lambda$ Red genes & This work \\
\hline E. coli KI2 MGI655 & Wild type & VKPM \\
\hline \multicolumn{3}{|l|}{ Plasmids } \\
\hline RSFIOIO & GenBank accession number $\underline{N C \quad 00 I 740}$ & {$[26]$} \\
\hline pUC4K & GenBank accession number $\underline{\mathrm{X06404}}$ & {$[32]$} \\
\hline $\mathrm{PMW}-a t t L_{\lambda}-\mathrm{Km}^{\mathrm{R}}-a t t R_{\lambda}$ & Donor $a t t L_{\lambda}-\mathrm{Km}^{\mathrm{R}}$-att $R_{\lambda}$ cassette; $\mathrm{Ap}^{\mathrm{R}} ; \mathrm{Km}^{\mathrm{R}}$ & {$[35]$} \\
\hline pKD46 & pINT-ts; $\lambda$ gam, bet, and exo genes are under $P_{\text {araB }}$ promoter; $A p^{R}$ & [4] \\
\hline pRSFRedTER & $\lambda$ gam, bet, and exo genes are under control of P-element; sacB gene; $\mathrm{Cm}^{R}$ & This work \\
\hline pRSFRedkan & $\lambda$ gam, bet, and exo genes are under control of P-element; $\mathrm{Km}^{\mathrm{R}}$ & This work \\
\hline pRSFGamBet & $\lambda$ gam and bet genes are under control of $\mathrm{P}$ - element; sacB gene; $\mathrm{Cm}^{\mathrm{R}}$ & This work \\
\hline pRSFGamBetkan & $\lambda$ gam and bet genes are under control of $\mathrm{P}$ - element; $\mathrm{Km}^{\mathrm{R}}$ & This work \\
\hline pRSFPlacsacB & $\mathrm{P}_{\text {lacUV5-sacB-cat cassette; } \mathrm{Cm}^{\mathrm{R}}}$ & This work \\
\hline PMW-intxis-cat & $\mathrm{pSCI0I-ts;} \lambda$ xis-int genes transcribed from $\lambda \mathrm{P}_{\mathrm{R}}$ promoter under Clts857 control; $\mathrm{Cm}^{\mathrm{R}}$ & This work \\
\hline
\end{tabular}

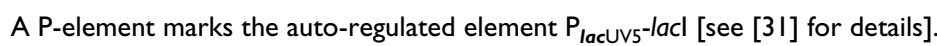

\section{Media and Growth conditions}

E. coli and $P$. ananatis strains were cultivated with aeration in $\mathrm{LB}$ medium at $37^{\circ} \mathrm{C}$ and $34^{\circ} \mathrm{C}$, respectively. The following antibiotic concentrations were used to select transformants and to maintain the plasmids: $\mathrm{Km} \mathrm{-} 40 \mathrm{mg} / \mathrm{l}$, $\mathrm{Cm}-50 \mathrm{mg} / \mathrm{l}$. The M9 salt medium supplemented with galactose $(1 \mathrm{~g} / \mathrm{l})$ or glucose $(1 \mathrm{~g} / \mathrm{l})$ was used to select $\mathrm{Gal}{ }^{+}$ or $\mathrm{His}^{+}$cells.

\section{Recombinant DNA techniques}

DNA manipulations were performed according to standard methods [58]. Restrictases were provided by "Fermentas" (Lithuania). T4-DNA ligase was from Promega (USA). All reactions were performed according to the manufacturer's instructions. PCR was carried out with Taqpolymerase ("Fermentas"). Primers were purchased from "Syntol" (Russia). All primers used in this work are listed in Additional file 2.

\section{Construction of integrative cassettes}

To provide cassettes for $\lambda$ Red-dependent integration, the appropriate selective marker was amplified by PCR with oligos containing on their 5'-ends 36-nt sequences homologous to the target region. To disrupt E. coli galK and $P$. ananatis hisD genes, a removable $\mathrm{Km}^{\mathrm{R}}$ marker flanked by $a t t L_{\lambda}$ and $a t t R_{\lambda}$ was amplified with galK-5/galK3 and hisD-5/hisD-3 primers, respectively. The pMW$a t t L_{\lambda}-\mathrm{Km}^{\mathrm{R}}-a t t R_{\lambda}$ plasmid was used as DNA template. To obtain insertion into the $P$. ananatis his $D$ gene, the $\mathrm{P}_{\mathrm{lac}^{-}}$ sacB-cat cassette was amplified in PCR with his-Plac-5/hiscat-3 primers using pRSFPlacsacB plasmid as template.

\section{Construction of the linear dsDNA fragment to exchange native Smal recognition site in the $P$. ananatis his $D$ gene by $\mathrm{Xhol}$ site}

First, his-Xhol-1 and his-XhoI-2 oligos complementary to each other were annealed. Both oligos contained sequences corresponding to the XhoI restriction site in the center and arms homologous to the sequence surrounding native SmaI site of the $P$. ananatis his $D$. As a result, the short dsDNA fragment containing the XhoI recognition site in its center and 33 bp long arms homologous to the target region, was obtained. The obtained fragment was amplified and extended by PCR with the primers his-SL and his-SR. The resultant DNA fragment generated by PCR contained XhoI recognition site in its center flanked with 82 bp arms homologous to the appropriate site in $P$. ananatis hisD gene.

\section{Plasmid electro-transformation}

An overnight culture of $P$. ananatis strain grown at $34^{\circ} \mathrm{C}$ with aeration was diluted with fresh LB broth 100 times and the cultivation was continued up to the $\mathrm{OD}_{600}=0.5-$ 0.8. Cells from ten millilitres were washed three times with an equal volume of deionized ice water followed by washing with $1 \mathrm{ml}$ of $10 \%$ cold glycerol and resuspended in $35 \mu \mathrm{l}$ of $10 \%$ cold glycerol. Just before electroporation, 10-100 ng of the plasmid DNA dissolved in $2 \mu \mathrm{l}$ of deionized water was added to the cell suspension. The procedure of plasmid electro-transformation was performed using the GenePulser and Pulse Controller ("BioRad", USA). The applied pulse parameters were: electric field strength of $20 \mathrm{kV} / \mathrm{cm}$, time constant of $5 \mathrm{msec}$. After electroporation, $1 \mathrm{ml}$ of LB medium enriched with glucose (5 $\mathrm{g} / \mathrm{l})$ was immediately added to the cell suspension. Then the cells were cultivated under aeration at $34^{\circ} \mathrm{C}$ for $2 \mathrm{~h}$ and plated on LB-agar containing the appropriate antibi- 
otic. This was followed by an overnight incubation at $34^{\circ} \mathrm{C}$. A competence of $P$. ananatis cells, determined for RSF1010 plasmid, was $10^{6} \mathrm{CFU}$ per $\mu \mathrm{g}$ of DNA. Typically, $10^{5}-10^{6}$ antibiotic resistant colonies were obtained per $10^{8}$ survivors following electroporation.

\section{Gene rearrangement}

Overnight cultures of $P$. ananatis or $E$. coli strains harbouring the plasmid, expressing appropriate $\lambda$ Red genes, grown in LB broth with Cm (for pRSFRedTER, pRSFGamBet plasmids) or Km (for pRSFRedkan, pRSFGamBetkan plasmids) were diluted 100 times with the same fresh medium supplemented with $1 \mathrm{mM}$ IPTG for induction of the $\lambda$ Red genes. At culture density of $0.5-0.6$, electrocompetent cells were prepared as described above. From 200 to $500 \mathrm{ng}$ of a PCR-generated linear dsDNA or $100 \mathrm{ng}$ of a ss-oligos were used for transformation. Electroporation was carried out at electric field strength of $25 \mathrm{kV} / \mathrm{cm}$ and time constant of $5 \mathrm{msec}$ for both types of DNA substrates. The chromosome structure of the obtained transformants was verified in PCR with galK-t1/galK-t2 primers for $E$. coli galK gene disruption, hisD-t1/hisD-t2 for $P$. ananatis hisD gene disruption and for insertion of the double selective/contra-selective marker into the P. ananatis hisD.

Gene disruption provided with pKD46 plasmid was performed as described in (4).

\section{P. ananatis electro-transformation with chromosomal DNA}

Cells were grown in LB medium up to $\mathrm{OD}_{600}=0.8-1.0$. Electro-competent cells were prepared as described above. From 1 to $2 \mathrm{mg}$ of a chromosomal DNA, isolated using a Genomic DNA Isolation Kit (Sigma), was used for transformation. Electroporation was carried out with an electric field strength of $12.5 \mathrm{kV} / \mathrm{cm}$ and time constant of 10 msec.

\section{SDS-PAGE}

SDS-PAGE of cell extracts was performed according to Laemmli [59] with polyacrylamide gel with linear gradient of concentrations from $10 \%$ to $15 \%$.

\section{Abbreviations}

Ap: ampicillin; $\mathrm{Ap}^{\mathrm{R}}$ : ampicillin resistance; $\mathrm{Cm}$ : chloramphenicol; $\mathrm{Cm}^{\mathrm{R}}$ : chloramphenicol resistance; cat: chloramphenicol resistance gene; $\mathrm{Km}$ : kanamycin; $\mathrm{Km}^{\mathrm{R}}$ : kanamycin resistance; kan: kanamycin resistance gene; sacB: gene encoding the levansucrase; att $L_{\lambda}$ : attL site of phage $\lambda ;$ att $R_{\lambda}$ : attR site of phage $\lambda ; a t t B_{\lambda}: a t t B$ site of phage $\lambda$; IPTG: isopropyl- $\beta$-D-thiogalactopyranoside; nt: nucleotide; bp: base pair(s); oligos: oligonucleotides; PCR: polymerase chain reaction; ssDNA: single-stranded DNA; dsDNA: double-stranded DNA.

\section{Authors' contributions}

JIK and YH are the project leaders in AGRI and in Ajinomoto, respectively. JIK obtained SC17(0), designed the main experiments concerned with $\lambda$ Red-driven modifications, and drafted the manuscript. YH developed the transfer of $\lambda$ Red-driven mutations to $P$. ananatis strains differed from SC17(0). LIG constructed all recombinant plasmids, expressing $\lambda$ Red genes, tested their function initially in $E$. coli, and edited the manuscript. TMK performed the $\lambda$ Red-driven modifications of the chromosome of $P$. ananatis SC17(0) strain. IGA performed $\lambda$ Red-driven oligos integration into chromosome of $P$. ananatis SC17 strain. SVM supervised and coordinated the work and edited the manuscript. All authors have read and approved the final version of the manuscript.

\section{Additional material}

\section{Additional file 1}

Plasmids constructed for this study.

Plasmids constructed for this study. Detailed description of plasmids constructed in this study.

Click here for file

[http://www.biomedcentral.com/content/supplementary/14712199-10-34-S1.doc]

\section{Additional file 2}

Primers used for this study.

Primers used for this study. List of primers.

Click here for file

[http://www.biomedcentral.com/content/supplementary/14712199-10-34-S2.doc]

\section{Acknowledgements}

Authors acknowledge Prof. B.L. Wanner kindly provided us with BW25 I I3/pKD46 strain. This study was carried out at the request of and with financial support from the Ajinomoto Co.

\section{References}

I. Izui H, Hara Y, Sato M, Akiyoshi N: Method for producing Lglutamic acid. United States Patent .

2. Murphy KC: Use of bacteriophage $\lambda$ recombination functions to promote gene replacement in Escherichia coli. J Bacteriol 1998, 180:2063-207|.

3. Zhang Y, Buchholtz F, Muyrers JPP, Stewart AF: A new logic for DNA engineering using recombination in Escherichia coli. Nature Genetics 1998, 20:123-128.

4. Datsenko KA, Wanner BL: One-step inactivation of chromosomal genes in Escherichia coli KI 2 using PCR products. Proc Natl Acad Sci USA 2000, 97:6640-6645.

5. Murphy KC, Campellone KG, Poteete AR: PCR-mediated gene replacement in Escherichia coli. Gene 2000, 246:321-330.

6. Yu D, Ellis HM, Lee EC, Jenkins NA, Copeland NG, Court DL: An efficient recombination system for chromosome engineering in Escherichia coli. Proc Natl Acad Sci USA 2000, 97:5978-5983.

7. Zhang Y, Muyrers JP, Testa G, Stewart AF: DNA cloning by homologous recombination in Escherichia coli. Nat Biotechnol 2000, 18:1314-1317.

8. Ellis HM, Yu D, DiTizio T, Court LD: High efficiency mutagenesis, repair, and engineering of chromosomal DNA using single- 
stranded oligonucleotides. Proc Natl Acad Sci USA 200I, 98:6742-6746.

9. Karu AE, Sakaki Y, Echols $H$, Linn S: The gamma protein specified by bacteriophage $\lambda$. Structure and inhibitory activity for the RecBC enzyme of Escherichia coli. J Biol Chem 1975, 250:7377-7387.

10. Murphy KC: $\lambda$ Gam protein inhibits the helicase and chi-stimulated recombination activities of Escherichia coli recBCD enzyme. J Bacteriol I99I, I73:5808-582I.

II. Little JW: An exonuclease induced by bacteriophage $\lambda$. II. Nature of the enzymatic reaction. J Biol Chem 1967, 242:679-686.

12. Carter DM, Radding CM: The role of exonuclease and $\beta$ protein of phage $\lambda$ in genetic recombination. II. Substrate specificity and the mode of action of lambda exonuclease. I Biol Chem 1971, 246:2502-25I2.

13. Cassuto E, Lash T, Sriprakash KS, Radding CM: The role of exonuclease and $\beta$ protein of phage $\lambda$ in genetic recombination. $V$. Recombination of $\lambda$ DNA in vitro. Proc Natl Acad Sci USA 197I, 68:1639-1643

14. Hill SA, Stahl MM, Stahl FM: Single-strand DNA intermediates in phage $\lambda$ 's Red recombination pathway. Proc Natl Acad Sci USA 1997, 94:295I-2956.

15. Muniyappa K, Radding CM: The homologous recombination system of phage $\lambda$. Pairing activities of $\beta$ protein. J Biol Chem 1986 26 I:7472-7478.

16. Mythili E, Kumar KA, Muniyappa K: Characterization of the DNA-binding domain of $\beta$ protein, a component of $\lambda$ Redpathway, by UV catalyzed cross-linking. Gene 1996, I 82:8I-87.

17. Li Z, Karakousis G, Chiu SK, Reddy G, Radding CM: The $\beta$ protein of phage $\lambda$ promotes strand exchange. J Mol Biol 1998 276:733-744.

18. Murphy KC, Campellone KG: Lambda Red-mediated recombinogenic engineering of enterohemorrhagic and enteropathogenic E. coli. BMC Mol Biol 2003, 4: I I.

19. Husseiny MI, Hensel M: Rapid method for the construction of Salmonella enterica serovar Typhimurium vaccine carrier strains. Infect Immun 2005, 73(3): 1598-1605.

20. Karlinsey JE: Lambda-Red genetic engineering in Salmonella enterica serovar Typhimurium. Methods Enzymol 2007 , 42I:199-209.

21. Shi Z-X, Wang H-L, Hu K, Feng E-L, Yao X, Su G-F, Huang P-T, Huang L-Y: Identification of alkA gene related to virulence of Shigella flexneri $2 \boldsymbol{a}$ by mutational analysis. World J Gastroenterol 2003 9:2720-2725

22. Ranallo RT, Barnoy S, Thakkar S, Urick T, Venkatesan MM: Developing live Shigella vaccines using lambda red recombineering. FEMS Immunol Med Microbiol 2006, 47:462-469.

23. Derbise A, Lesic B, Dacheux D, Ghigo JM, Carniel E: A rapid and simple method for inactivating chromosomal genes in Yersinia. FEMS Immunol Med Microbiol 2003, 38: I I3-1 I6.

24. Lesic B, Bach S, Ghigo JM, Dobrindt U, Hacker J, Carniel E: Excision of the high-pathogenicity island of Yersinia pseudotuberculosis requires the combined actions of its cognate integrase and Hef, a new recombination directionality factor. Mol Microbiol 2004, 52:1337-1348.

25. Lesic B, Rahme LG: Use of the lambda Red recombinase system to rapidly generate mutants in Pseudomonas aeruginosa. BMC Mol Biol 2008, 9:20.

26. Scholz P, Haring V, Wittmann-Liebold B, Ashman K, Bagdasarian M, Scherzinger $E$ : Complete nucleotide sequence and gene organization of the broad-host-range plasmid RSF I0 I 0. Gene 1989 75:27I-288

27. Frey J, Bagdasarian M: The molecular biology of IncQ plasmids. In Promiscuous plasmids of Gram-negative bacteria Edited by: Thomas CM. New York: Academic Press, Inc; 1989:79-94.

28. Gormley EP, Davies I: Transfer of plasmid RSFI0 I 0 by conjugation from Escherichia coli to Streptomyces lividans and Mycabacterium smegmatis. J Bacteriol 1991, 173:6705-6708.

29. Brunschwig E, Darzins A: A two-component T7 system for the overexpression of genes in Pseudomonas aeruginosa. Gene | 992, I II:35-4I.

30. Dehio M, Knorre A, Lanz C, Dehio C: Construction of versatile high-level expression vectors for Bartonella henselae and the use of green fluorescent protein as a new expression marker. Gene 1998, 215:223-229.
31. Skorokhodova AYu, Katashkina Zhl, Zimenkov DV, Smirnov SV Gulevich AYu, Biriukova IV, Mashko SV: Design and study on characteristics of auto- and smoothly regulated genetic element O3/P lac UV5/O lac $\rightarrow$ lacl. Biotechnologiya (Russian) 2004, 5:3-2 I.

32. Taylor LA, Rose RE: $\mathbf{A}$ correction in the nucleotide sequence of the Tn903 kanamycin resistance determinant in pUC4K. Nucleic Acids Res 1988, 16:358.

33. Rabilloud T: Proteome research: two-dimensional gel electrophoresis and identification methods Berlin: Springer; 2000

34. Peredelchuk MY, Bennett GN: A method for construction of $E$. coli strains with multiple DNA insertion in the chromosome. Gene 1997, 187:231-238.

35. Minaeva NI, Gak ER, Zimenkov DV, Skorokhodova AYu, Biryukova IV, Mashko SV: Dual-In/Out strategy for genes integration into bacterial chromosome: a novel approach to step-by-step construction of plasmid-less marker-less recombinant $E$. coli strains with predesigned genome structure. BMC Biotechnology 2008, 8:63.

36. Katashkina JI, Golubeva LI, Kuvaeva TM, Gaidenko TA, Gak ER, Mashko SV: Method for constructing recombinant bacterium belonging to the genus Pantoea and method for producing Lamino acids using bacterium belonging to the genus Pantoea. Russian Federation Patent application . 2006I34574.

37. Kilbane JJ 2nd, Bielaga BA: Instantaneous gene transfer from donor to recipient microorganism via electroporation. Biotechniques 1991, 10:354-365.

38. Choi KH, Kumar A, Schweizer HP: A 10-min method for preparation of highly electrocompetent Pseudomonas aeruginosa cells: application for DNA fragment transfer between chromosomes and plasmid transformation. I Microbiol Methods 2006, 64:391-397.

39. Sheng YuL, Mancino V, Birren B: Transformation of Escherichia coli with large DNA molecules by electroporation. Nucleic Acids Res 1995, 23:1990-1996.

40. Muyrers JJP, Zhang Y, Benes V, Testa G, Ansorge W, Stewart AF: Point mutation of bacterial artificial chromosomes by ET recombination. EMBO reports 2000, I:239-243.

4I. Heermann R, Zeppenfeld T, Jung K: Simple generation of sitedirected point mutations in the Escherichia coli chromosome using $\operatorname{Red}^{\circledR} /$ ET $^{\circledR}$ recombination. Microbial Cell Factories 2008, 7:14.

42. Li X, Costantino N, Lu L, Liu D, Watt RM, Cheah KSE, Court DL, Huang J-D: Identification of factors influencing strand bias in oligonucleotide-mediated recombination in Escherichia coli. Nucleic Acids Res 2003, 31:6674-6687.

43. Swaminathan S, Ellis HM, Waters LS, Yu D, Lee E-C, Court DL, Sharan SK: Rapid engineering of bacterial artificial chromosomes using oligonucleotides. Genesis 200I, 29:|4-2I.

44. Datta S, Costantino N, Court DL: A set of recombineering plasmids for gram-negative bacteria. Gene 2006, 379: I09- II5.

45. Thomason LC, Costantino N, Shaw DV, Court DL: Multicopy plasmid modification with phage $\lambda$ Red recombineering. Plasmid 2007, 58: | 48- I58.

46. Friedman SA, Hays BH: Selective inhibition of Escherichia coli activities by plasmid-encoded Gams function of phage lambda. Gene 1986, 43:255-263.

47. Sergueev K, Yu D, Austin S, Cuort D: Cell toxicity caused by products of the $p(L)$ operon of bacteriophage lambda. Gene 200I, 227:227-235

48. Court DL, Sawitzke JA, Thomason LC: Genetic engineering using homologous recombination. Annu Rev Genet 2002, 36:36I-388.

49. Sawitzke JA, Thomason LC, Costantino N, Bubuenko M, Datta S, Court $D L$ : Recombineering: In vivo genetic engineering in $E$. coli, S. enterica, and beyond. Methods Enzymol 2007, 42 I: I7I-I99.

50. Enquist LW, Skalka A: Replication of bacteriophage $\lambda$ DNA dependent on the function of host and viral genes. I. Interaction of red, gam and rec. J Mol Biol 1973, 75:185-2/2.

51. Silberstein Z, Cohen A: Synthesis of linear multimers of OriC and PBR322 derivatives in Escherichia coli K-12: role of recombination and replication functions. I Bacteriol 1987 169:3|3|-3|37.

52. Silberstein Z, Maor S, Berger I, Cohen A: Lambda Red-mediated synthesis of plasmid linear multimers in Escherichia coli $\mathrm{K} I 2$. Mol Gen Genet 1990, 223:496-507. 
53. Murphy $\mathrm{K}: \lambda$ Gam protein inhibits the helicase and $\chi$-stimulated activities of Escherichia coli RecBCD enzyme. J Bacteriol 1991, 173:5808-582I.

54. Dale EC, Ow DW: Gene transfer with subsequent removal of the selection gene from the host genome. Proc Natl Acad Sci USA 1991, 88: 10558-10562.

55. Posfai G, Koob M, Hradecna Z, Hasan N, Filutowich M, Szybalski W: In vivo excision and amplification of large segments of the Escherichia coli genome. Nucleic Acids Res 1994, 22:2392-2398.

56. Cherepanov PP, Wackernagel W: Gene disruption in Escherighia coli : TcR and KmR cassettes with the option of FLP-catalyzed excision of the antibiotic-resistance determinant. Gene 1995, I 58:9-14.

57. Kristensen CS, Eberl L, Sanchez-Romero JM, Givskov M, Molin S, De Lorenzo V: Site-specific deletions of chromosomally located DNA segments with the multimer resolution system of broad-host-range plasmid RP4. J Bacteriol 1995, 177:52-58.

58. Sambrook J, Fitsch EF, Maniatis T: Molecular Cloning: A Laboratory Manual Cold Spring Harbor: Cold Spring Harbor Press; 1989.

59. Laemmli UK: Cleavage of structural proteins during the assembly of the head of bacteriophage T4. Nature 1970, 227:680-685.

Publish with Bio Med Central and every scientist can read your work free of charge

"BioMed Central will be the most significant development for disseminating the results of biomedical research in our lifetime. "

Sir Paul Nurse, Cancer Research UK

Your research papers will be:

- available free of charge to the entire biomedical community

- peer reviewed and published immediately upon acceptance

- cited in PubMed and archived on PubMed Central

- yours - you keep the copyright 